\title{
A review of 173 cases of myelomeningocele seen in a tertiary referral fetal management unit over a 12 year period Carys M Bannister* and Jared Burki
}

Address: Fetal Management Unit, St Mary's Hospital, Hathersage Road, Manchester, UK

Email: Carys M Bannister* - carysban@aol.com

* Corresponding author

from 49th Annual Meeting of the Society for Research into Hydrocephalus and Spina Bifida Barcelona, Spain, 29 June -2 July 2005

Published: 30 December 2005

Cerebrospinal Fluid Research 2005, 2(SuppI I):SI5 doi:I0.II86/1743-8454-2-SI-SI5

\section{Background}

173 pregnant women with a myelomeningocele (MMC) affected fetus were referred to St Mary's Hospital between January 1991 and December 2002. The number of cases referred each year was greatest in 1993 and 1998 and least in 1995. The termination rate increased from a low of $43 \%$ in 1994 to a high of over $90 \%$ in 2000, 2001 and 2002.

\section{Materials and methods}

The Cortical Index (BPD-2xVA) was calculated for the fetuses from data collected at the time of the anomaly ultrasound scan carried out at 18 to 20 weeks of gestation.

\section{Results}

The majority of cases had a Cortical Index of less than 32 (mean value for fetuses without a MMC). There was a trend for the higher vertebral level MMCs to have the smallest Cortical Indices but there were many exceptions.

\section{Conclusion}

Of the 173 cases only 23 (13\%) developed hydrocephalus, i.e. progressive increase in the ventricular atrium size with a concurrent disproportionate increase in the head circumference. There was no correlation between the vertebral level of the MMC and hydrocephalus. 